\title{
Physicochemical Properties, Baking Performance and Sensory Evaluation of Bakery Shortening Enriched with Diacylglycerol
}

\author{
Noor Hidayu Othman, Ahmadilfitri Md Noor and Mohd Suria Affandi Yusoff \\ Sime Darby Research Sdn. Bhd., R\&D Centre-Downstream, Lot 2664, Jalan Pulau Carey, Pulau Carey 42960, Selangor, Malaysia
}

\begin{abstract}
The purpose of this study was to investigate the suitability of palm diacylglycerol (PDAG)-enriched formulations for bakery shortening. Three types of palm diacylglycerol olein (PDAGOL) at different degree of unsaturation (PDAGOLIV56, PDAGOLIV62 and PDAGOLIV64) were used as main raw materials blended with palm stearin (PS). The blending compositions ranged from $30 \%$ to $70 \%$ of PDAGOLIV56/PS, PDAGOLIV62/PS and PDAGOLIV64/PS, respectively. The physicochemical properties of all binary blend systems were characterized for fatty acid composition (FAC), slip melting point (SMP) and solid fat content (SFC). The selected bakery shortening formulations were further characterised for polymorphic form of fat crystal and thermal behavior, using X-ray diffractometer (XRD) and differential scanning calorimetry (DSC). Bakery shortening enriched with diacylglycerol that were produced from 40DS56 (40\% PDAGOLIV56/60\% PS), 40DS62 (40\% PDAGOLIV62/60\% PS) and 40DS64 (40\% PDAGOLIV64/60\% PS) had 45\%-50\% unsaturated fatty acid and crystallized in $\beta$ ' $+\beta$ polymorphs; thus they were suitable for shortening system. Based on product's baking performance, it could be found that all Madeira cakes prepared from bakery shortening enriched with diacylglycerol had higher specific cake volume as compared to commercial shortening (CS). In customer acceptance test, Madeira cake made from 40DS56 shortening scored the highest rating for all sensory attributes, including overall customer acceptability. It had given an indication that 40DS56 shortening formulation was the most suitable fat blends to be used as bakery shortening.
\end{abstract}

Key words: Diacylglycerol, shortening, baking, sensory.

\section{Introduction}

Generally, bakery shortening is produced from a mixture of liquid oil (soybean oil, cottonseed oil, rapeseed oil or a mixture of these oils) and solid fat (hydrogenated soybean oil, cottonseed oil, rapeseed oil, palm oil or animal fat) [1]. However, in the late of 20th century to early 21 st century, there was an attempt to include diacylglycerol (DAG) as one of the main component of bakery shortening to improve the nutritional properties of baked product [2]. Bakery shortening with DAG-enriched was found to produce cakes with better physical functionality. This is due to their content of both lipophilic (oil loving) and hydrophilic (water loving) groups in DAG, which has

Corresponding author: Noor Hidayu Othman, M.Sc., research fields: processing technology, oils and fats. E-mail: noor.hidayu.othman@simedarby.com. marked surface activity [3].

Diacylglycerol or also known as DAG is the esters of glycerol, which formed when two fatty acids are esterified onto a glycerol molecule. DAG can exist in three isomers, namely 1,2-DAG, 2,3-DAG and 1,3-DAG. The amount of DAG present in edible oils may vary with the origin of the oil. In general, palm oil contains up to $6 \%$ DAG [4]. DAG, which is categorized under a class of nutraceutical lipid, is able to manage obesity by decreasing postprandial lipid levels $[5,6]$, increasing $\beta$-oxidation of fat $[7,8]$, suppressing accumulation of visceral abdominal fat [9] and also reducing body weight [10]. According to Marangoni and Lencki [11], 40\% of DAG is required in edible fat composition to achieve DAG levels with beneficial health effects [11].

The aim of this study was to investigate the 
compatibility of DAG-enriched formulations to be used in shortening production. Five binary blends at composition ranging from $30 \%$ to $70 \%$ palm diacylglycerol olein (PDAGOL) were developed from three binary blend systems (PDAGOLIV56/PS, PDAGOLIV62/PS and PDAGOLIV64/PS). The fatty acid composition (FAC), slip melting point (SMP), solid fat content (SFC), differential scanning calorimetry (DSC) and x-ray diffraction (XRD) of all binary blends were examined and compared with the commercial shortening (CS). The selected fat blends enriched with DAG from each binary blend system were used to produce DAG shortening. The baking performance of Madeira cakes prepared from DAG shortening and CS were evaluated in term of specific cake volume. The sensory evaluations of Madeira cakes were carried out using untrained panellist to examine the customer's acceptability of DAG shortening for baking application as compared to $\mathrm{CS}$.

\section{Materials and Methods}

\subsection{Raw Materials}

Crude palm diacylglycerol (PDAG) was produced by enzymatic glycerolysis and purified using short path distillation (SPD) at R\&D Research Centre, Carey Island. The purified PDAG that had high DAG content (more than $80 \%$ DAG) was used to produce various palm diacylglycerol olein (PDAGOL), namely PDAGOLIV56, PDAGOLIV62 and PDAGOLIV64 using $50 \mathrm{~kg}$ dry-fractionation pilot plant. Palm stearin (PS) was obtained from Sime Darby Jomalina Sdn. Bhd., Telok Panglima Garang. JOMA ${ }^{\mathrm{TM}}$ shortening that used as a CS was made from palm oil and PS.

\subsection{Sample Preparation}

Five binary formulations of various PDAGOL with PS were prepared at molar fraction of $\mathrm{X}_{\mathrm{PDAGOL}}=0.3$, $0.4, \quad 0.5, \quad 0.6, \quad 0.7$ for three blending systems -PDAGOLIV56/PS, PDAGOLIV62/PS and
PDAGOLIV64/PS. Each blend was produced in triplicates for further analysis.

\section{$2.3 S M P$}

SMP was measured according to AOCS method Cc.3.25 [12]. The clean capillary tubes were dip into a liquid sample and filled with $1 \mathrm{~cm}$ high of melted fat. The capillary tubes were rolled against a piece of ice until fat solidified. Then it was transferred into a small beaker and placed into a water bath at $10{ }^{\circ} \mathrm{C}$ for $16 \mathrm{~h}$. Subsequently, the capillary tubes were attached to a thermometer and suspended in a $600 \mathrm{~mL}$ beaker of cool distilled water at $4{ }^{\circ} \mathrm{C}$. The distilled water was heated on the hot plate operated with magnetic stirrer at a rate of $1{ }^{\circ} \mathrm{C} / \mathrm{min}$. The temperature at which the fat column rises was reported as the SMP.

\subsection{FAC}

FAC of fat blends were determined by the rapid method of AOCS official method Cd 14c-94 [12]. FAC analysis was done by gas chromatography (model: Autosystem XL, Perkin Elmer, USA). Fatty acids present in oil were first converted to fatty acid methyl esters (FAME) before being injected into polar $\mathrm{SP}^{\mathrm{TM}}$ (Supelco, Bellefonte, PA) capillary column $(0.25 \mathrm{~mm}$ i.d. $\times 60 \mathrm{~m} \times 0.2 \mu \mathrm{m})$, to obtain the fatty acid profiles.

\section{$2.5 S F C$}

The SFC of fat blends were measured according to the Malaysian Palm Oil Board (MPOB) test method p4.8 [13]. The samples were analyzed using Bruker minispec pulsed-nuclear magnetic resonance (pNMR) (model No. 120; Hamburg, German). The sample in the nuclear magnetic resonance (NMR) tube was melted at $70{ }^{\circ} \mathrm{C}$ for $30 \mathrm{~min}$, followed by chilling at $0{ }^{\circ} \mathrm{C}$ for $90 \mathrm{~min}$ prior to measurement. Melting, chilling and holding of the sample were carried out in a pre-equilibrated thermostat water bath. The percentage of SFC was analyzed at a set 
temperature of $5,10,15,20,25,30,35,40,45,50$, 55 and $60{ }^{\circ} \mathrm{C}$.

\subsection{DSC}

Thermal properties of fat blends were measured using DSC from PerkinElmer (PerkinElmer Inc., Bridgeport Avenue, Shelton, USA). The data processor was PerkinElmer diamond DSC auto-sampler. Nitrogen ( $99.9 \%$ purity) was used as the purge gas and flowed at $20.0 \mathrm{~mL} / \mathrm{min}$. The DSC instrument was calibrated with indium (melting point $\left.157^{\circ} \mathrm{C}\right)$.

\subsection{XRD Analysis}

The polymorphic forms of fat crystals were determined with an FR592 Enraf-Nonius Diffractis $\mathrm{X}$-ray generator (Delft, The Netherlands) and an Enraf-Nonius model FR 552 Guinier camera equipped with a customized single-compartment cell with the temperature controlled by an external-circulating thermostatic bath. The melted sample at $60{ }^{\circ} \mathrm{C}$ was placed in the cell, which was set at the crystallization temperature $(T c)$. Sample was held isothermally until all the polymorphic phases were fully observed.

\subsection{Production of Shortening}

The selected binary blends of 40DS56 (X $\left.=0.4 ; \mathrm{X}_{\mathrm{PS}}=0.6\right), 40 \mathrm{DS} 62\left(\mathrm{X}_{\mathrm{PDAGOLIV} 62}=0.4 ; \mathrm{X}_{\mathrm{PS}}=\right.$ $0.6)$ and 40DS64 ( $\left.\mathrm{X}_{\text {PDAGOLIV64 }}=0.4 ; \mathrm{X}_{\mathrm{PS}}=0.6\right)$ were selected to produce bakery shortening. The fat blend was stirred at $70{ }^{\circ} \mathrm{C}$ for about $30 \mathrm{~min}$ to erase the crystal memory until it was completely homogenized. Then the melted blend was stirred at $20{ }^{\circ} \mathrm{C}$ for about $20 \mathrm{~min}$, followed by at $10{ }^{\circ} \mathrm{C}$ until it texturized and formed a shortening. The CS shortening followed similar method with DAG shortening production. Both shortenings were then stored at room temperature $\left(25^{\circ} \mathrm{C}\right)$.

\subsection{Baking Performance in Madeira Cakes}

The recipe for Madeira cake was shown in Table 1.
Firstly, shortening was mixed with sugar using a Kenwood Premier Chef model KMC570 mixer at speed 3 for $5 \mathrm{~min}$. The eggs were added one by one followed by vanilla flavour. Dry ingredients including all-purpose flour, self-rising flour, sugar and salt were mixed until the homogenous dispersion was formed. The homogenous dry ingredients were then added into a batter and mixed using a Kenwood Premier Chef model KMC570 mixer at speed 2 for 3 min. Finally, the batter was placed into two round cake baking tins (internal diameter $140 \mathrm{~mm}$ i.d.) for about $400 \mathrm{~g}$, which were lined with grease roof papers and baked in oven at $160{ }^{\circ} \mathrm{C}$ for about $1 \mathrm{~h}$. Rapeseed displacement method was used to measure the weight and volume of cakes once it was sufficiently cooled. Then, the specific volumes of cakes were measured.

\subsection{Sensory Evaluation}

Sensory evaluation of Madeira cakes was evaluated through customer acceptance test. This acceptance test involved 30 untrained panellists randomly picked from R\&D Laboratory (Downstream), Carey Island. Madeira cakes were cut into slices with thickness 1 $\mathrm{cm}$ and square cutter $3 \mathrm{~cm} \times 3 \mathrm{~cm}$. All cake samples were coded with three-digit random numbers and presented randomly to the untrained panellists. The panellists were asked to rate their degree of liking or disliking of the cake sample using hedonic scales that rated from 1 (extremely dislike) to 9 (extremely like) and neutral category at the centre of the scale. The sensory attributes were evaluated based on colour, texture, aroma, taste and overall acceptability.

Table 1 Madeira cake recipe.

\begin{tabular}{ll}
\hline Ingredient & Content \\
\hline Self-rising flour & $150 \mathrm{~g}$ \\
All-purpose flour & $100 \mathrm{~g}$ \\
Shortening & $175 \mathrm{~g}$ \\
Egg & 3 whole \\
Castor sugar & $175 \mathrm{~g}$ \\
Salt & A pinch of salt \\
Flavour & $1 \mathrm{~mL}$ \\
\hline
\end{tabular}


Table 2 SMP of binary blends enriched with DAG and CS.

\begin{tabular}{llll}
\hline Blending composition & PDAGOLIV56/PS & PDAGOLIV62/PS & PDAGOLIV64/PS \\
\hline $\mathrm{X}_{\mathrm{PDAGOL}}=0.0$ & $50.00 \pm 0.12$ & $51.00 \pm 0.07$ & $51.00 \pm 0.07$ \\
$\mathrm{X}_{\mathrm{PDAGOL}}=0.3$ & $43.53 \pm 0.12$ & $45.25 \pm 0.07$ & $44.00 \pm 0.00$ \\
$\mathrm{X}_{\mathrm{PDAGOL}}=0.4$ & $43.27 \pm 0.23$ & $43.05 \pm 0.07$ & $42.85 \pm 0.07$ \\
$\mathrm{X}_{\mathrm{PDAGOL}}=0.5$ & $41.00 \pm 0.35$ & $42.50 \pm 0.00$ & $41.85 \pm 0.07$ \\
$\mathrm{X}_{\mathrm{PDAGOL}}=0.6$ & $40.40 \pm 0.20$ & $41.40 \pm 0.14$ & $40.45 \pm 0.07$ \\
$\mathrm{X}_{\mathrm{PDAGOL}}=0.7$ & $38.27 \pm 0.23$ & $27.45 \pm 0.07$ & $30.90 \pm 0.00$ \\
$\mathrm{X}_{\mathrm{PDAGOL}}=1.0$ & $33.33 \pm 0.31$ & $24.85 \pm 0.07$ & $22.10 \pm 0.14$ \\
$\mathrm{CS}$ & $46.87 \pm 0.05$ & $46.87 \pm 0.05$ & $46.87 \pm 0.05$ \\
\hline
\end{tabular}

\section{Results and Discussion}

\subsection{SMP}

Table 2 shows the SMP of binary blends enriched with DAG (PDAGOLIV56, PDAGOLIV62 and PDAGOLIV64) and CS. PDAGOLIV56 with higher composition of palmitic acid (C16) had SMP of $33.3{ }^{\circ} \mathrm{C}$ as compared to PDAGOLIV62 and PDAGOLIV64 with SMP of $24.85{ }^{\circ} \mathrm{C}$ and $22.10^{\circ} \mathrm{C}$, respectively. PS that comprised more saturated fatty acid (SAFA) content had high SMP of 50-51 ${ }^{\circ} \mathrm{C}$; CS had SMP of $46.87{ }^{\circ} \mathrm{C}$. Hence, the binary blends of various PDAGOL with PS are important in producing the desired SMP of bakery shortening. Addition of 40\%-70\% PS into PDAGOLIV56/PS, PDAGOLIV62/PS and PDAGOLIV64/PS had produced a suitable SMP range for bakery shortening application between $40.4^{\circ} \mathrm{C}$ and $45.25^{\circ} \mathrm{C}$.

\subsection{FAC}

Table 3 shows the FAC of binary blends enriched with DAG (PDAGOLIV56/PS, PDAGOLIV62/PS and PDAGOLIV64/PS) and CS. The major fatty acid found in CS was palmitic acid (50.34\% C16), followed by oleic acid (35.30\% C18-1). PS also had high composition of palmitic acid (approximately $55.5 \% \mathrm{C} 16$ ), followed by oleic acid (approximately 31\% C18-1). Inversely, PDAGOLIV56, PDAGOLIV62 and PDAGOLIV64 had high composition of oleic acid (47.6\%-53\% $\mathrm{C} 18-1)$, followed by palmitic acid (30.5\%-36.78\% C16). Addition of $30 \%-70 \%$ PS to PDAGOLIV56,
PDAGOLIV62 and PDAGOLIV64 had increased the amount of saturated fatty acid (SAFA) from $47.5 \%$ to $56.48 \%$ (PDAGOLIV56/PS), $43.64 \%$ to $54.3 \%$ (PDAGOLIV62/PS) and $40.86 \%$ to $52.59 \%$ (PDAGOLIV64/PS), respectively. Meanwhile, the amount of unsaturated fatty acid (MUFA and PUFA) had decreased from $52.52 \%$ to $43.52 \%$ (PDAGOLIV56/PS), $\quad 56.35 \%$ to $\quad 45.7 \%$ (PDAGOLIV62/PS) and $65.61 \%$ to $47.41 \%$ (PDAGOLIV64/PS), respectively. All binary blend systems had closed FAC profile with $\mathrm{CS}$ at fat blends of $\mathrm{X}_{\mathrm{PDAGOL}}=0.3-0.4$.

\subsection{SFC}

Fig. 1 shows the SFC curve of PDAGOLIV56, PS, PDAGOLIV56/PS blends and CS by using NMR method. PDAGOLIV56 had $10.72 \% \mathrm{SFC}$ at $25{ }^{\circ} \mathrm{C}$ (room temperature), $3.37 \% \mathrm{SFC}$ at $37{ }^{\circ} \mathrm{C}$ (body temperature) and completely liquid at $50{ }^{\circ} \mathrm{C}$. Meanwhile, PS had high SFC content $50.2 \%$ at $25{ }^{\circ} \mathrm{C}$, $19.8 \% \mathrm{SFC}$ at $37{ }^{\circ} \mathrm{C}$ and completely liquid at $55^{\circ} \mathrm{C}$. Addition of $30 \%-70 \%$ PS to PDAGOLIV56 had increased the fat content of PDAGOLIV56/PS blends from $16 \%$ to $30.36 \% \mathrm{SFC}$ at $25{ }^{\circ} \mathrm{C}$ and from $6.7 \%$ to $14 \% \mathrm{SFC}$ at $37^{\circ} \mathrm{C}$.

The SFC curve of PDAGOLIV62, PS, PDAGOLIV62/PS blends and CS are shown in Fig. 2. PDAGOLIV62 had 5.26\% $\mathrm{SFC}$ at $25{ }^{\circ} \mathrm{C}$ and completely liquid at $37{ }^{\circ} \mathrm{C}$. Addition of $30 \%-70 \%$ PS to PDAGOLIV62 had increased the fat content of PDAGOLIV62/PS blends from $12.58 \%$ to $31.13 \%$ $\mathrm{SFC}$ at $25^{\circ} \mathrm{C}$ and from $3.2 \%$ to $11 \% \mathrm{SFC}$ at $37^{\circ} \mathrm{C}$. The 
Table 3 FAC of binary blends enriched with DAG and CS.

\begin{tabular}{|c|c|c|c|c|c|c|c|}
\hline \multirow{2}{*}{ Fat blends } & \multicolumn{7}{|c|}{ Fatty acid composition (\%) } \\
\hline & $\mathrm{C} 16$ & $\mathrm{C} 18$ & C18:1 & C18:2 & SAFA & MUFA & PUFA \\
\hline \multicolumn{8}{|c|}{ PDAGOLIV56/PS } \\
\hline $\mathrm{X}_{\mathrm{PDAGOL}}=0.0$ & $55.49 \pm 0.07$ & $4.97 \pm 0.03$ & $30.94 \pm 0.06$ & $6.56 \pm 0.03$ & $62.03 \pm 0.04$ & $31.02 \pm 0.07$ & $6.95 \pm 0.04$ \\
\hline $\mathrm{X}_{\mathrm{PDAGOL}}=0.3$ & $50.50 \pm 0.11$ & $4.46 \pm 0.08$ & $35.60 \pm 0.18$ & $7.44 \pm 0.03$ & $56.48 \pm 0.18$ & $35.73 \pm 0.18$ & $7.79 \pm 0.02$ \\
\hline $\mathrm{X}_{\mathrm{PDAGOL}}=0.4$ & $48.37 \pm 0.15$ & $4.36 \pm 0.00$ & $37.49 \pm 0.10$ & $7.80 \pm 0.06$ & $54.25 \pm 0.17$ & $37.62 \pm 0.09$ & $8.16 \pm 0.05$ \\
\hline $\mathrm{X}_{\mathrm{PDAGOL}}=0.5$ & $46.43 \pm 0.04$ & $4.19 \pm 0.01$ & $39.10 \pm 0.03$ & $8.22 \pm 0.03$ & $52.14 \pm 0.04$ & $39.27 \pm 0.02$ & $8.59 \pm 0.04$ \\
\hline $\mathrm{X}_{\mathrm{PDAGOL}}=0.6$ & $44.50 \pm 0.04$ & $4.03 \pm 0.03$ & $40.86 \pm 0.08$ & $8.54 \pm 0.11$ & $50.09 \pm 0.01$ & $40.98 \pm 0.08$ & $8.94 \pm 0.11$ \\
\hline $\mathrm{X}_{\mathrm{PDAGOL}}=0.7$ & $42.14 \pm 0.06$ & $3.81 \pm 0.01$ & $42.87 \pm 0.04$ & $8.99 \pm 0.05$ & $47.50 \pm 0.04$ & $43.01 \pm 0.01$ & $9.51 \pm 0.04$ \\
\hline $\mathrm{X}_{\mathrm{PDAGOL}}=1.0$ & $36.78 \pm 0.06$ & $3.37 \pm 0.04$ & $47.58 \pm 0.17$ & $9.94 \pm 0.25$ & $41.71 \pm 0.14$ & $47.75 \pm 0.18$ & $10.55 \pm 0.06$ \\
\hline \multicolumn{8}{|c|}{ PDAGOLIV62/PS } \\
\hline $\mathrm{X}_{\mathrm{PDAGOL}}=0.0$ & $55.69 \pm 0.25$ & $4.94 \pm 0.04$ & $30.78 \pm 0.08$ & $6.53 \pm 0.04$ & $62.18 \pm 0.18$ & $30.92 \pm 0.10$ & $6.90 \pm 0.08$ \\
\hline $\mathrm{X}_{\mathrm{PDAGOL}}=0.3$ & $48.47 \pm 0.01$ & $4.30 \pm 0.01$ & $36.96 \pm 0.01$ & $8.08 \pm 0.01$ & $54.30 \pm 0.04$ & $37.15 \pm 0.01$ & $8.55 \pm 0.05$ \\
\hline $\mathrm{X}_{\mathrm{PDAGOL}}=0.4$ & $46.13 \pm 0.02$ & $4.08 \pm 0.01$ & $39.07 \pm 0.04$ & $8.59 \pm 0.01$ & $51.71 \pm 0.01$ & $39.23 \pm 0.04$ & $9.06 \pm 0.04$ \\
\hline $\mathrm{X}_{\mathrm{PDAGOL}}=0.5$ & $43.68 \pm 0.04$ & $3.86 \pm 0.02$ & $41.17 \pm 0.08$ & $9.09 \pm 0.04$ & $49.05 \pm 0.01$ & $41.34 \pm 0.08$ & $9.62 \pm 0.05$ \\
\hline $\mathrm{X}_{\mathrm{PDAGOL}}=0.6$ & $41.37 \pm 0.02$ & $3.64 \pm 0.02$ & $43.26 \pm 0.08$ & $9.53 \pm 0.08$ & $46.51 \pm 0.01$ & $43.45 \pm 0.09$ & $10.04 \pm 0.10$ \\
\hline $\mathrm{X}_{\mathrm{PDAGOL}}=0.7$ & $38.75 \pm 0.21$ & $3.38 \pm 0.01$ & $45.38 \pm 0.19$ & $10.18 \pm 0.07$ & $43.64 \pm 0.23$ & $45.60 \pm 0.16$ & $10.75 \pm 0.07$ \\
\hline $\mathrm{X}_{\mathrm{PDAGOL}}=1.0$ & $31.58 \pm 0.03$ & $2.81 \pm 0.11$ & $51.75 \pm 0.11$ & $11.60 \pm 0.11$ & $35.78 \pm 0.21$ & $51.99 \pm 0.09$ & $12.21 \pm 0.16$ \\
\hline \multicolumn{8}{|c|}{ PDAGOLIV64/PS } \\
\hline $\mathrm{X}_{\mathrm{PDAGOL}}=0.0$ & $55.69 \pm 0.25$ & $4.94 \pm 0.04$ & $30.78 \pm 0.08$ & $6.53 \pm 0.04$ & $62.18 \pm 0.18$ & $30.92 \pm 0.10$ & $6.90 \pm 0.08$ \\
\hline $\mathrm{X}_{\mathrm{PDAGOL}}=0.3$ & $46.90 \pm 0.08$ & $4.17 \pm 0.11$ & $38.26 \pm 0.07$ & $8.47 \pm 0.01$ & $52.59 \pm 0.17$ & $38.45 \pm 0.12$ & $8.97 \pm 0.05$ \\
\hline $\mathrm{X}_{\mathrm{PDAGOL}}=0.4$ & $44.02 \pm 0.25$ & $3.90 \pm 0.06$ & $41.03 \pm 0.23$ & $8.83 \pm 0.18$ & $49.44 \pm 0.35$ & $41.21 \pm 0.23$ & $9.37 \pm 0.12$ \\
\hline $\mathrm{X}_{\mathrm{PDAGOL}}=0.5$ & $38.21 \pm 0.12$ & $3.53 \pm 0.10$ & $45.85 \pm 0.09$ & $10.05 \pm 0.06$ & $43.26 \pm 0.04$ & $46.09 \pm 0.04$ & $10.65 \pm 0.00$ \\
\hline $\mathrm{X}_{\mathrm{PDAGOL}}=0.6$ & $36.60 \pm 0.18$ & $3.24 \pm 0.05$ & $47.35 \pm 0.19$ & $10.54 \pm 0.17$ & $41.34 \pm 0.18$ & $47.60 \pm 0.15$ & $11.17 \pm 0.18$ \\
\hline $\mathrm{X}_{\mathrm{PDAGOL}}=0.7$ & $36.11 \pm 0.16$ & $3.26 \pm 0.12$ & $47.98 \pm 0.01$ & $10.37 \pm 0.33$ & $40.86 \pm 0.30$ & $48.18 \pm 0.00$ & $10.97 \pm 0.30$ \\
\hline $\mathrm{X}_{\mathrm{PDAGOL}}=1.0$ & $30.49 \pm 0.32$ & $2.65 \pm 0.06$ & $52.91 \pm 0.13$ & $11.74 \pm 0.00$ & $34.48 \pm 0.16$ & $53.17 \pm 0.18$ & $12.34 \pm 0.02$ \\
\hline $\mathrm{CS}$ & $50.34 \pm 0.02$ & $4.61 \pm 0.06$ & $35.30 \pm 0.04$ & $7.62 \pm 0.08$ & $56.51 \pm 0.06$ & $35.42 \pm 0.04$ & $8.07 \pm 0.10$ \\
\hline
\end{tabular}

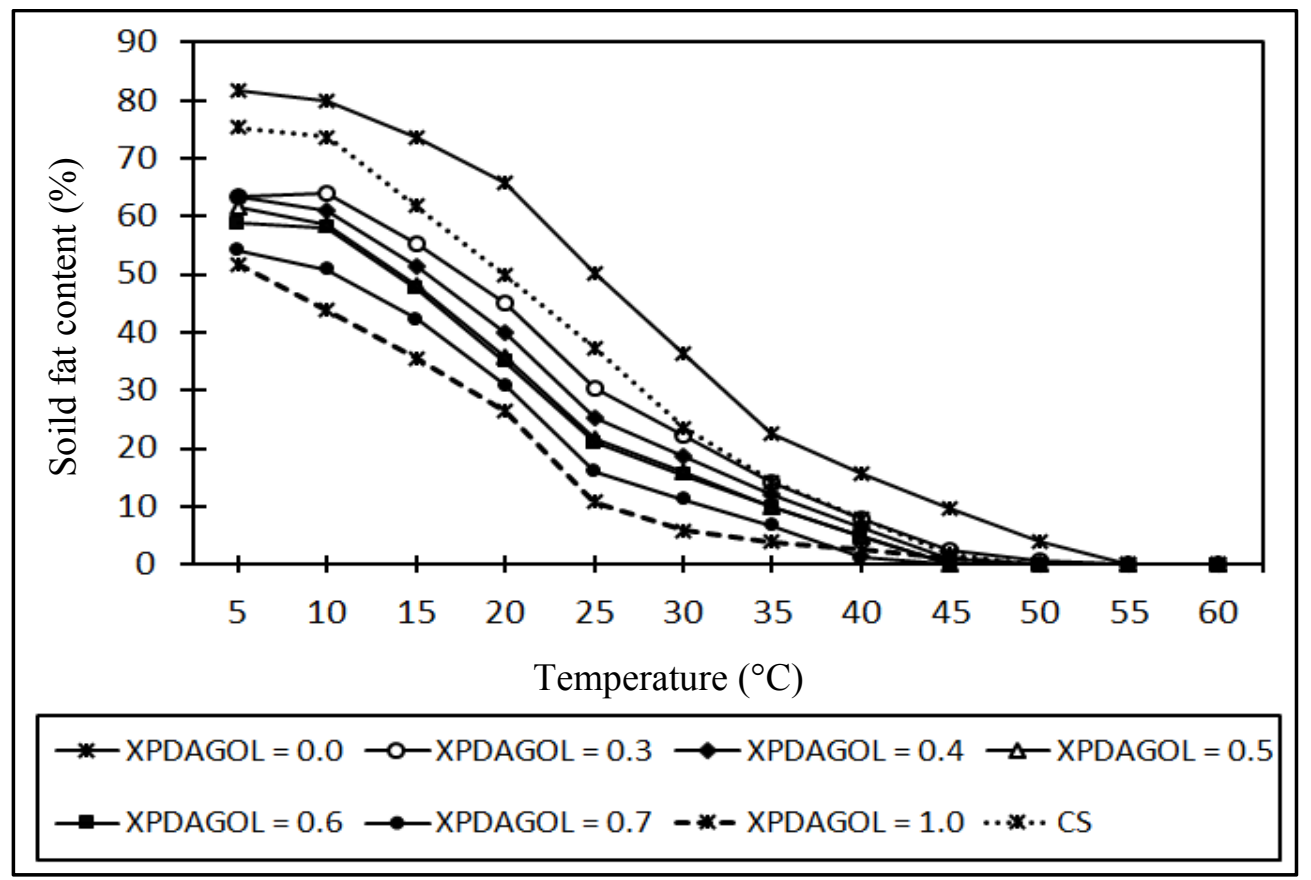

Fig. 1 SFC of PDAGOLIV56/PS blends and CS. 


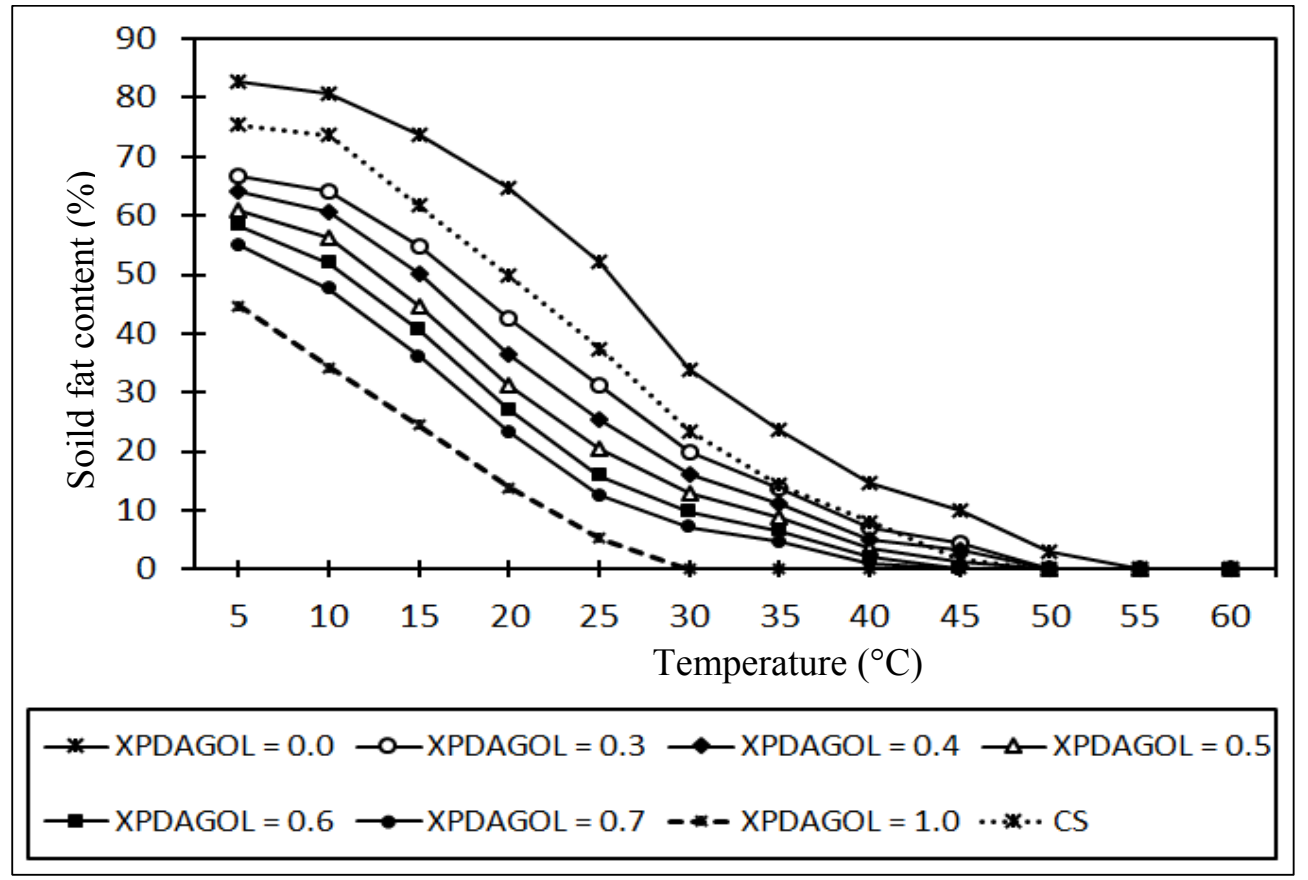

Fig. 2 SFC of PDAGOLIV62/PS blends and CS.

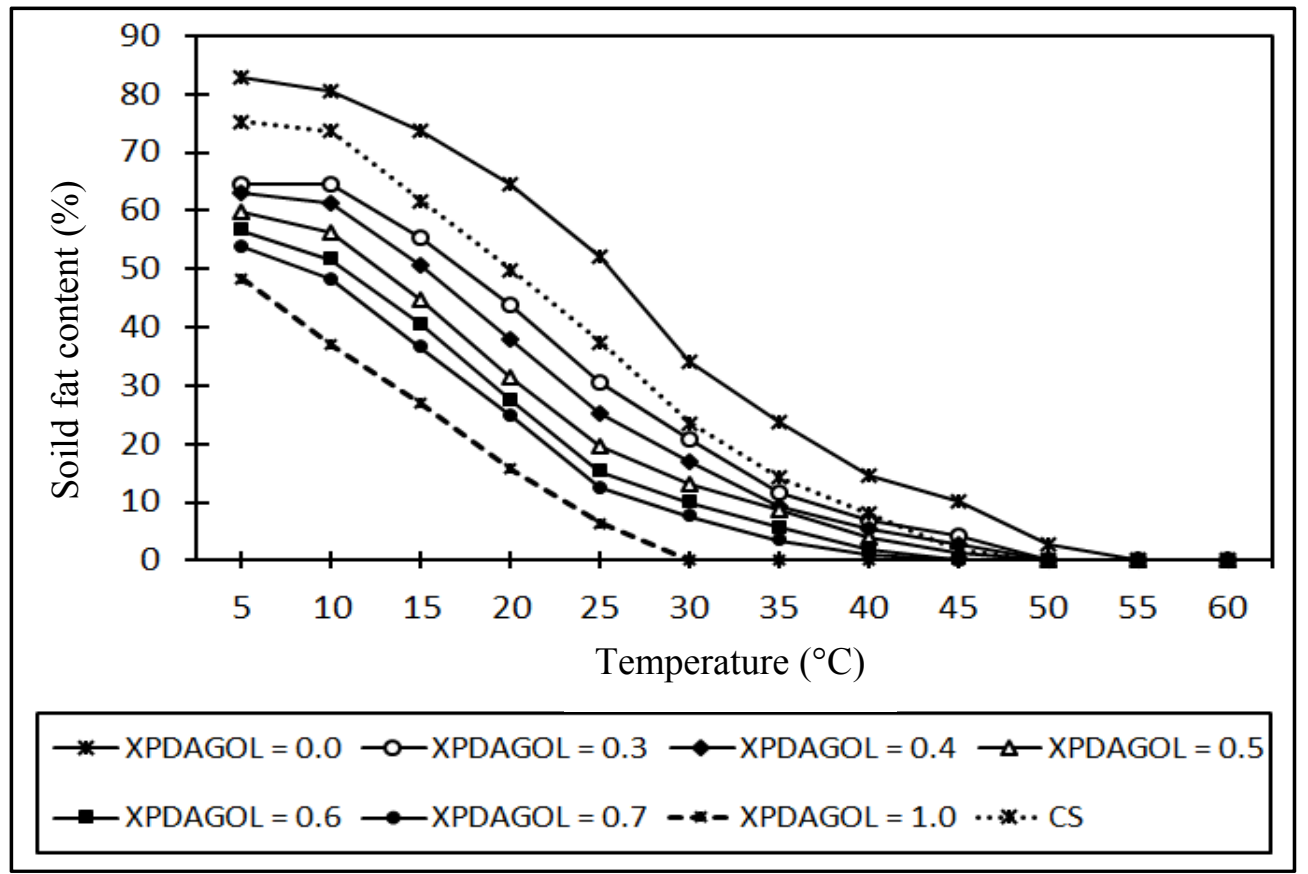

Fig. 3 SFC of PDAGOLIV64/PS blends and CS.

SFC of PDAGOLIV64/PS blends and CS are shown in Fig. 3. PDAGOLIV64 had $6.41 \% \mathrm{SFC}$ at $25{ }^{\circ} \mathrm{C}$ and completely liquid at $37{ }^{\circ} \mathrm{C}$. Addition of $30 \%-70 \%$ PS to PDAGOLIV64 had increased the fat content of PDAGOLIV64/PS blends from $12.46 \%$ to $30.51 \%$ SFC at $25{ }^{\circ} \mathrm{C}$ and from $2.43 \%$ to $9.83 \%$ SFC at $37{ }^{\circ} \mathrm{C}$.
For optimum baking performance, bakery shortening should have a minimum of $20 \%$ SFC at $25{ }^{\circ} \mathrm{C}$ and also a minimum of $5 \% \mathrm{SFC}$ at high temperature $\left(40{ }^{\circ} \mathrm{C}\right)$. This is to encourage the structural formation of cake for baking application [14]. CS had $37.4 \% \mathrm{SFC}$ at $25{ }^{\circ} \mathrm{C}$ and $7.97 \% \mathrm{SFC}$ at 
$40{ }^{\circ} \mathrm{C}$, which is within the specification of optimum SFC profile for bakery shortening. Meanwhile, from the binary blends of PDAGOLIV56/PS, PDAGOLIV62/PS and PDAGOLIV64/PS, the optimum SFC profile was recorded at $\mathrm{X}_{\mathrm{PDAGOL}}=$ 0.3-0.4.

\subsection{DSC}

The DSC melting thermograms shown in Fig. 4 can be divided into three melting fractions, known as low melting fraction (LMF), medium melting fraction (MMF) and high melting fraction (HMF). CS had broad shoulder melting peak (P3 and P4) at MMF region and small melting peak (P5) at HMF region. This may due to the complex nature of fats and oil that comprised various types of triglycerides. CS was completely melted at $51{ }^{\circ} \mathrm{C}$. Meanwhile, all DAG shortening (40DS56, 40DS62 and 40DS64) had very high and sharp melting peak (P2) up to $22^{\circ} \mathrm{C}$ at MMF region, broad melting peak $(\mathrm{P} 3)$ in a range of $46.55^{\circ} \mathrm{C}$ to $48.6^{\circ} \mathrm{C}$ at $\mathrm{HMF}$ region and small melting peak (P1) at LMF region. 40DS64 was completely melted at $51{ }^{\circ} \mathrm{C}$, followed by $40 \mathrm{DS} 62$ at $51.5^{\circ} \mathrm{C}$ and 40DS56 at $52.2{ }^{\circ} \mathrm{C}$. It seems that all DAG shortening had closed end melting temperature, where the oils and fats were completely melted. This had improved the compact texture of cake produced from the stearin fraction of PDAG [15] and further improved the cake volume.

\subsection{Subcell Packing and Polymorphs}

The subcell packing and polymorphs of DAG shortenings (40DS56, 40DS62, and 40DS64) and CS are shown in Table 4. $\beta$ ' polymorph consists of small, uniform needle-like crystals, which are densely packed in orthorhombic perpendicular subcell $(\mathrm{O} \pm)$ [16]. $\beta$ ' form is the most functional and desirable in shortening due to its better crystalline network and thin-needle shape morphology. These results in smoother texture, better aeration and excellent creaming properties in cake shortening [14]. The transformation of crystal from $\beta$ ' form to more stable $\beta$ form that densely packed in triclinic parallel subcell packing is unfavourable, because it results in deterioration of the end product [17]. However, the metastable $\beta^{\prime}+\beta$ polymorph is the most desirable for bakery shortening system. All the selected DAG shortenings had crystallized in $\beta^{\prime}+\beta$ polymorphs similar to CS.

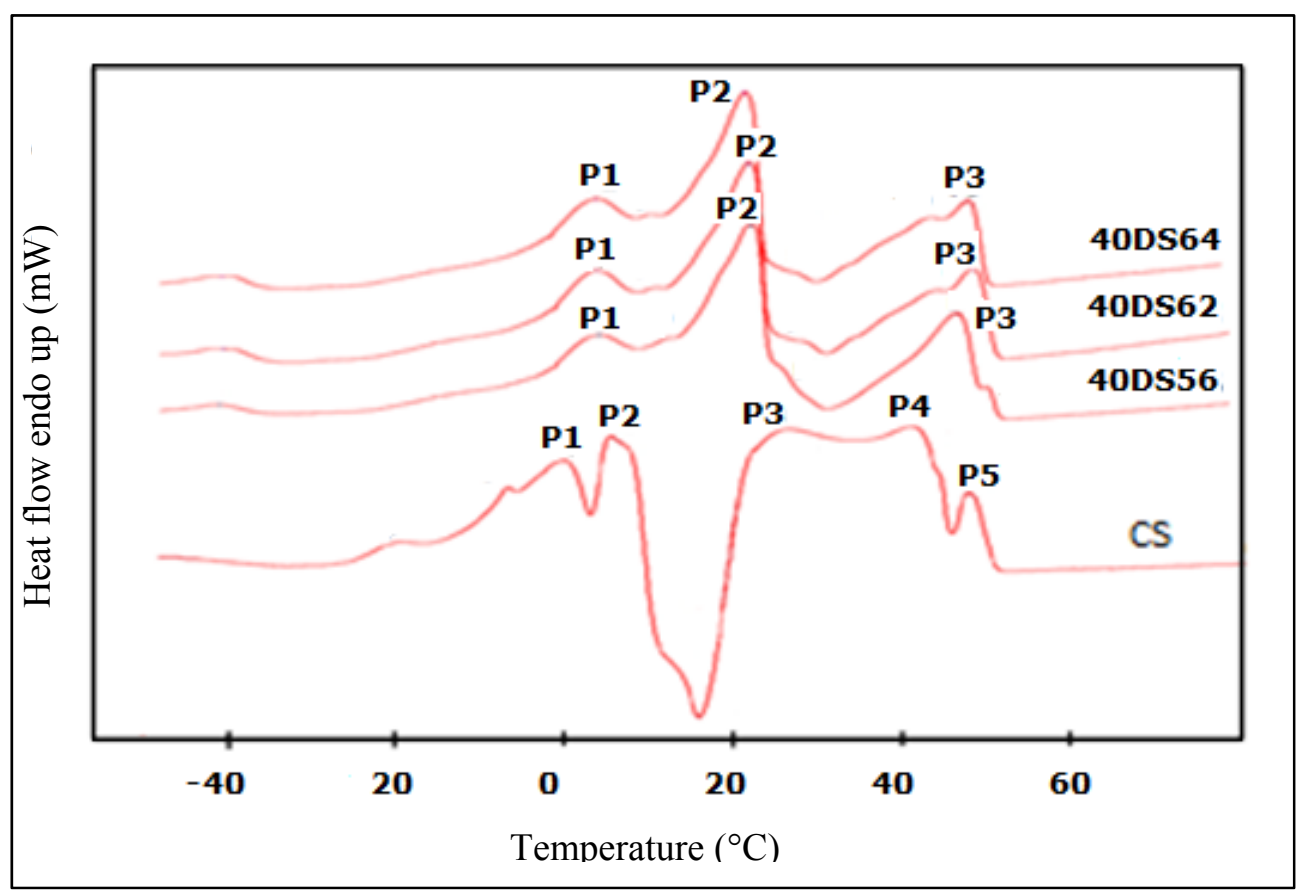

Fig. 4 DSC melting curve of DAG shortenings and CS. 
Table 4 Subcell packing and polymorphs of DAG shortenings (40DS56, 40DS62 and 40DS64) and CS.

\begin{tabular}{lll}
\hline Shortening & Subcell packing & Polymorphic form \\
\hline 40DS56 & $\mathrm{O}_{\wedge}+\mathrm{T}_{/ /}$ & $\beta^{\prime}+\beta$ \\
40DS62 & $\mathrm{O}_{\wedge}+\mathrm{T}_{/ /}$ & $\beta^{\prime}+\beta$ \\
40DS64 & $\mathrm{O}_{\wedge}+\mathrm{T}_{/ /}$ & $\beta^{\prime}+\beta$ \\
CS & $\mathrm{O}_{\wedge}+\mathrm{T}_{/ /}$ & $\beta^{\prime}+\beta$ \\
\hline
\end{tabular}

All $\beta^{\prime}+\beta$ polymorphs was categorised under orthorhombic perpendicular $\left(\mathrm{O}^{\wedge}+\mathrm{T} / /\right)$ subcell packing.

Table 5 Specific volume and percentage of specific volume of Madeira cakes prepared from DAG shortenings (40DS56, 40DS62, and 40DS64) and CS.

\begin{tabular}{lllll}
\hline Shortening & CS & 40DS56 & 40DS62 & 40 DS64 \\
\hline Specific volume of cake $\left(\mathrm{cm}^{3} / \mathrm{g}\right)$ & 2.2 & 2.35 & 2.36 & 2.22 \\
Specific volume of cake $(\%$ of CS) & $\mathrm{n} / \mathrm{a}$ & $107 \%$ & $109 \%$ & $101 \%$ \\
\hline
\end{tabular}

$\mathrm{n} / \mathrm{a}$ : not applicable, because the $\%$ of specific volume was calculated by comparing the specific volume of Madeira cakes prepared from DAG shortening vs. CS.

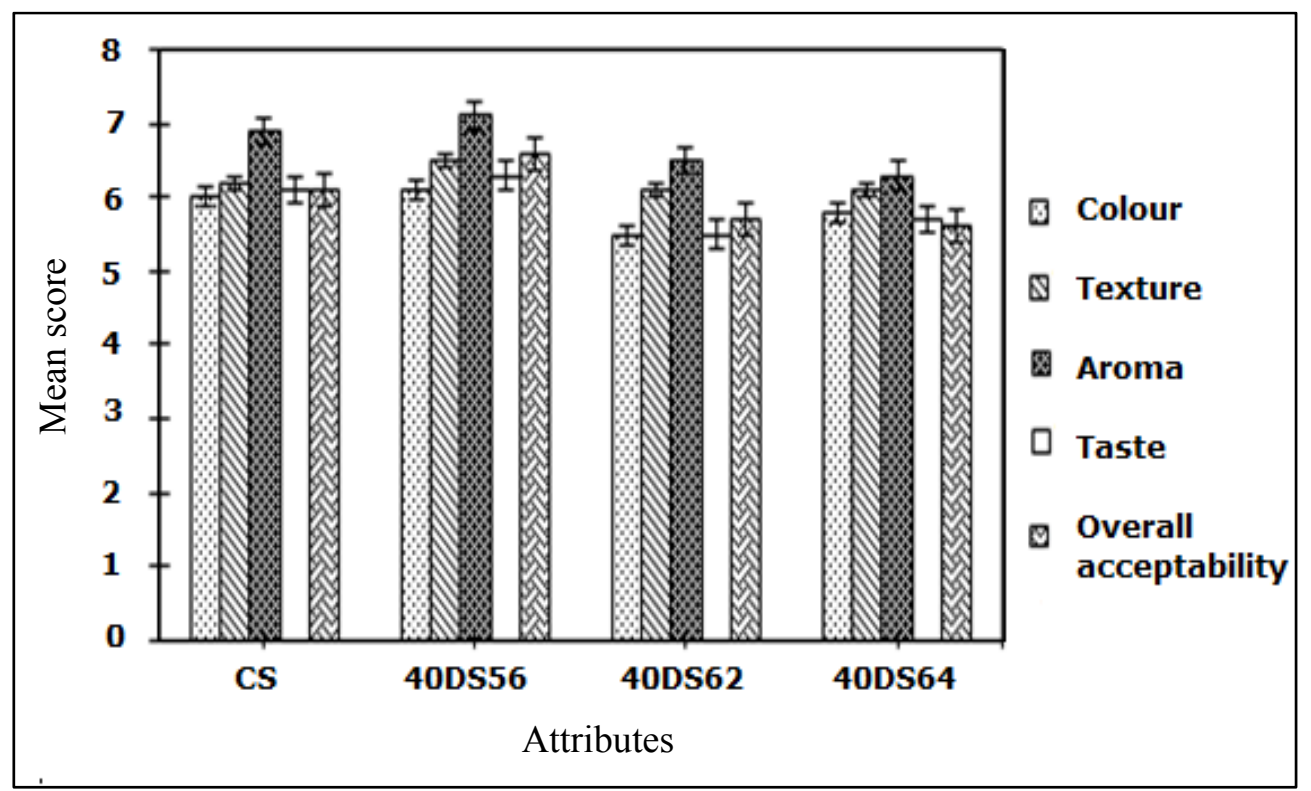

Fig. 5 Sensory evaluation of Madeira cakes made from DAG shortenings and CS.

\subsection{Baking Performance in Madeira Cakes}

The baking performance of Madeira cakes is shown in Table 5. All Madeira cakes made from DAG shortenings had higher percentage of specific cake volume up to $109 \%$ as compared to CS. Similar results were reported by Sikorski [2] that cake baked from DAG shortening had the higher cake volume. Fig. 5 shows the sensory evaluation of Madeira cakes prepared from DAG shortenings (40DS56, 40DS62 and 40DS64) and CS for customer acceptance test using hedonic scale. Cake made from 40DS56 had the highest mean values for all sensory attributes for colour, texture, aroma, taste and overall acceptability. Cake made from CS had the second highest score in all sensory attributes. Nevertheless, other two cakes made from 40DS62 and 40DS64 were also acceptable as panellist rated at least five in all attributes.

\section{Conclusions}

FAC of DAG-enriched formulation had a great influence on the SFC and heating behaviour of bakery shortening. All DAG shortening produced from 40DS56, 40DS62 and 40DS64 had the higher unsaturated FAC as compared to CS. Apart from that, the present of more DAG content in the shortening 
system showed the appearance of sharp medium melting fraction peak as compared to the normal DAG-enriched formulation of CS. In term of baking performance, Madeira cakes prepared from all DAG shortenings had the higher specific volume of cake as compared to CS. Nevertheless, panellists of sensory evaluation rated Madeira cake made from 40DS56 shortening the highest mean value for all sensory attributes. The results from physicochemical properties, baking performance and sensory evaluation had provided an indication that 40DS56 shortening formulation was the most suitable fat blends to be used as bakery shortening.

\section{Acknowledgments}

The authors would like to acknowledge Sime Darby Research Sdn. Bhd. for the financial and technical support.

\section{References}

[1] Ghotra, B. S., Dyal, S. D., and Narine, S. S. 2002. "Lipid Shortening: A Review." Food Res. Int. 35: 1015-48.

[2] Sikorski, D. 2004. "Application of Diacylglycerol Oil in Baked Goods, Nutritional Beverages/Bars, Sauces and Gravies.” In Diacylglycerol Oils, edited by Katsugi, Y., Yasukawa, T., Matsui, N., Flickinger, B. D., Tokimitsu, I., and Matlock, M. G. Illinois, USA: AOCS Press, 223-52.

[3] Chrysam, M. M. 2005. "Margarine and Spreads." In Bailey's Industrial Oil and Fats Products, 6th ed., edited by Shahidi, F. Vol. 4. New York: John Wiley and Sons Inc., 33-73.

[4] Matsuo, N. 2004. "Digestion, Metabolism and Health Benefit of Diacylglycerols." Malaysian Oil Sci. Technol. 113: 30-40.

[5] Taguchi, H., Watanabe, H., Onizawa, K., Nagao, T., Gotoh, N., and Yasukawa, T. 2000. "Double-Blind Controlled Study on the Effects of Dietary Diacylglycerol on Postprandial Serum and Chylomicron Triacylglycerol Responses in Healthy Humans.” J. Am. Coll. Nutr. 19 (6): 789-96.

[6] Tada, N., Watanabe, H., Matsuo, N., Tokimitsu, I., and Okazaki, M. 2000. "Dynamics of Postprandial Remnant Like Lipoprotein Particles in Serum after Loading of Diacylglycerols." Clin. Chim. Acta 311 (2): 109-17.

[7] Murata, M., Ide, T., and Hara, K. 1997. "Reciprocal
Responses to Dietary Diacylglycerolof Hepatic Enzymes of Fatty Acid Synthesis and Oxidation in the Rat." Br. J. Nutr. 77 (1): 107-21.

[8] Murase, T., Mizuno, T., Omachi, T., Onizawa, K., Komine, Y., Kondo, H., Hase, T., and Tokinitsu, I. 2001. "Dietary Diacylglycerol Suppresses High Fat and High Sucrose Diet-Induced Body Fat Accumulation in C57BL/6J Mice." J. Lipid Res. 42 (3): 372-8.

[9] Nagao, T., Watanabe, H., Goto, N., Onizawa, K., Taguchi, H., Matsuo, N., Yasukawa, T., Tsushima, R., Shimasaki, H., and Itakura, H. 2000. "Dietary Diacylglycerol Suppresses Accumulation of Body Fat Compared to Triacylglycerol in Men in a Double-Blind Controlled Trial." J. Nutr. 130 (4): 792-7.

[10] Maki, K. C., Davidson, M. H., Tsushima, R., Matsuo, N., Tokimitsu, I., Umporowicz, D. M., and Dicklin, M. R. 2002. "Consumption of Diacylglycerol Oil as Part of a Reduced-Energy Diet Enhances Loss of Body Weight and Fat in Comparison with Consumption of a Triacylglycerol Control Oil.” Am. J. Clin. Nutr. 76 (6): 1230-6.

[11] Marangoni, A. G., and Lencki, R. W. 1998. "Ternary Phase Behavior of Milk Fat Fractions.” J. Agric. Food Chem. 46 (10): 3879-84.

[12] AOCS. 1993. Official and Tentative Methods of the American Oil Chemists' Society. Champaign, Illinois: AOCS Press.

[13] Aini, K., Siew, W. L., Tan, Y. A., Nor-Aini, I., Mokhtar, Y., Tang, T. S., and Nuzul, A. I. 2005. "Methods of Test for Palm Oil and Palm Oil Products: Determination of Solid Fat Content by Pulsed Nuclear Magnetic Resonance (PNMR) Section 1: Direct Method." In MPOB Test Method. Kuala Lumpur: Malaysia Palm Oil Board, 36670.

[14] Podmore, J. 2002 "Bakery Fats." In Fats in Food Technology, edited by Rajah, K. K. Sheffied, UK: CRC Press, 30-68.

[15] Latip, R. A., Lee, Y. Y., Tang, T. K., Phuah, E. T., Tan, C. P., and Lai, O. M. 2013. "Physicochemical Properties and Crystallisation Behaviour of Bakery Shortening Produced from Stearin Fraction of Palm-Based Diacyglycerol Blended with Various Vegetable Oils." J. Food Chem. 141 (4): 3938-46.

[16] Sato, K. 2001. "Crystallization Behaviour of Fats and Lipids-A Review.” Chem. Eng. Sc. 56 (7): 2256-65.

[17] O'Brien, R. D. 2005. "Shortening: Types and Formulations." In Bailey's Industrial Oil and Fats Products, 6th ed., edited by Shahidi, F. Vol. 3. New York: John Wiley and Sons Inc., 125-56. 